\title{
Discurso del Rector de la Universidad Alas Peruanas, en la ceremonia de incorporación como Doctor Honoris Causa del Dr. Francisco Távara \\ Córdova, Presidente de la Corte Suprema de Justicia de la República
}

Fidel Ramírez Prado

Rector de la Universidad Alas Peruanas. Ph.D. en Business Administration. Doctor en Derecho y Ciencias Políticas. Magíster en Administración de Empresas.
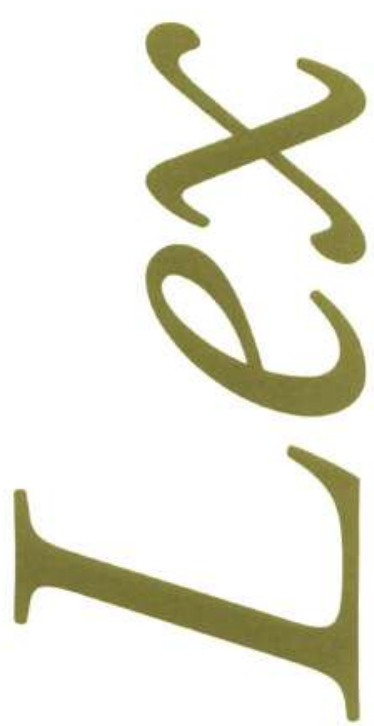


\section{EÑORES:}

La Universidad Alas Peruanas se viste de gala, una vez más, para recibir e incorporar a su Honrosa Galería de Doctores Honoris Causa al doctor:

\section{Francisco Artemio Távara Córdova}

Se trata de un hombre que ha sabido unir a su clara inteligencia y a su profesión, la tranquila espiritualidad que ennoblece al hombre; recibe, pues, el justo reconocimiento obtenido por méritos propios.

La vida del Dr. Távara ha estado identificada siempre con la pasión por el Derecho, con los ideales sagrados de la Justicia, con el cumplimiento irrestricto de la magistratura, con la magnificencia profunda del abogado, y, además, con la especulación epistemológica de la ciencia jurídica. Mención subrayada merece su profunda vocación como docente universitario, donde no solo exaltó la pureza de la cátedra, sino que hizo y forjó una verdadera Escuela de Derecho.

Por estas consideraciones, nuestra Universidad Alas Peruanas, lo distingue y lo condecora hoy con el Doctorado Honoris Causa.

Esta condecoración académica, que es la más significativa de nuestro Sistema Universitario, es a la vez el testimonio de reconocimiento a los hombres que dejan a su paso la huella inmaculada de su grandeza, de su mística, de su entrega y devoción, siempre en su afán por lograr un mundo mejor, más humano y más justo, equitativo y axiológico.

Por eso exaltamos la personalidad del Dr. Francisco Távara, y por ello le otorgamos el DocTORADO Honoris CaUSA, para que las generaciones de los tiempos venideros vean en él un 
paradigma que alcanzar y un modelo que seguir. Ningún arte es tan difícil, ninguna literatura cala tan hondo y ningún conocimiento resulta tan complicado como el acto de hacer justicia.

En Mateo 5,6 de la Biblia se dice: «iBienaventurados los que tienen hambre y sed de justicia, porque ellos serán saciados!»

Ni Platón, ni Kant pudieron definir la Justicia, por la solemnidad que ella representa y los alcances que conlleva.

Bertrand Rusell dijo que la Justicia es la no arbitrariedad.

La Justicia es un valor humano, y por eso es subjetiva; mejor dicho, es creada por el hombre. No sucede lo mismo con los valores naturales como la verdad, el bien, la belleza, que son inexorables.

Al Dr. Francisco Távara lo caracterizan varias cualidades, las mismas que sirven para exaltar su personalidad y su don de humanista, así como el perfil singular de su figura.

Como todo abogado, sabe transformar la vida en lógica, y como Juez, sabe cambiar esa lógica en Justicia. Esto que pareciera paradoja, no lo es; aparece más bien como un camino excepcional y correcto.

En tal virtud, la abogacía resulta, al mismo tiempo que arte, política, ética y acción, una profesión con mente sin vacaciones.

Decía el Dr. Monroy Gálvez que «en cada abogado hay cuatro colegas: el abogado que creemos que somos, el que la comunidad cree que somos, el que realmente somos, y el que debemos ser». Y en este último afán, precisaba que el ejercicio de la abogacía exigía solidaridad, comprensión, empatía y sacrificio.

Estas cualidades son precisamente las que adornan al Dr. Távara Córdova. Él es un jurista, a no dudarlo.

En las grandes épocas del Derecho Romano se consideraba al Derecho como Derecho de Juristas.

Juristas son aquellos que sienten la belleza en la solución de un caso litigioso, resolviendo armoniosamente y con matices estéticos, lo que corresponda, con arreglo a la justicia. 
Los juristas bien pueden ser calificados como virtuosos, dado que la jurisdicción es una virtud, es decir, el poder para gobernar honestamente y poner en ejecución las leyes.

Aristóteles consideraba a la justicia como una virtud suprema.

Así pues, el Dr. Távara Córdova y todos los que somos abogados resultamos hombres de derecho.

Para el Dr. Távara el Derecho es una pasión excluyente. Él lo define como un camino inexorable y como una excelsa virtud, a través del cual la humanidad y, específicamente, el Perú, podrán lograr la unidad, identidad y el bienestar.

Decía también que el Derecho debe cristalizar la estabilidad y el fomento recíproco de la sociedad. El Derecho es una forma de organizar el mundo de acuerdo con valores superiores.

El Dr. Raúl Ferrero en un artículo publicado en el Diario El Comercio, en abril de 1997, se refería a la «misión social del Derecho», y expresaba que debía ser preocupación del abogado, promover el orden jurídico, como eje de la transformación social. Luchar por la Justicia es la lucha intensa del Derecho. El Derecho no es un fin, sino un medio para administrar la represión de las inconductas sociales. Desde este punto de vista, el Derecho involucra a la psicología, a la sociología, a la antropología, a la psiquiatría y aun a la metafísica. Esta es la multidiversidad de nuestra profesión.

Es bueno resaltar una inclinación apasionante del Dr. Távara Córdova, es un asiduo y ferviente amante de la literatura. Lo ha demostrado en más de una vez. Y es admirador del gran poeta universal César Vallejo.

Tanta es su admiración, que ha repetido lo que hizo el Papa Juan Pablo II cuando reivindicó al sabio Galileo Galilei, que había sido condenado por haber defendido la teoría heliocéntrica. Lo obligaron a abjurar de su teoría científica, pero sus palabras eternizadas fueron eppur si muove, es decir, «sin embargo, se mueve». Se refería al movimiento de la Tierra.

El Dr. Távara ha reivindicado a César Vallejo, quien fuera culpado injustamente de haber participado en una asonada del Subprefecto contra los gendarmes de esa época, y que concluyó con muertes. VALLEjo fue procesado y vejado, precisa e injustamente, en Trujillo.

El Dr. Távara ha expedido la Resolución de desagravio, firmándola también en esta ciudad de Trujillo, anulando los argumentos pueriles de aquella época (año 30) y limpiando a Vallejo del 
oprobio y del legicidio del que había sido víctima. Gesto histórico de nuestro Presidente del Poder Judicial, el Dr. Távara Córdova.

El Dr. Távara Córdova es en estos momentos Presidente de la Corte Suprema y a la vez Magistrado. En tal sentido, resulta el nervio y el espíritu de todos los abogados del país.

Es grandioso ser el guía espiritual de una entidad, porque permite iluminar conciencias, desbrozar caminos y fortalecer esperanzas.

Toda autoridad se fundamenta en la razón, porque la razón trae fe; y esto permite crear una cultura de vida, cuya aspiración máxima es el respeto a la dignidad humana.

Preocupación del Dr. Távara Córdova ha sido mejorar la vida ética del Poder Judicial, contribuir para encontrar el verdadero orden político e imponer una administración de justicia sin genuflexión. Ha propugnado un estrecho acercamiento con los medios de comunicación, para demostrar la limpieza de la función jurisdiccional y el debido proceso, insistiendo en la claridad del mismo.

Las generaciones jurídicas del país sabrán mantener una admiración sin reserva por la labor del Dr. Francisco Távara Córdova, como abogado, magistrado, jurista y Presidente del organismo máximo del Poder Judicial; lo harán reconociendo su talento creador y la brillantez de su pensamiento, divulgado en sus escritos, en los que se advierten juicios cristalinos de inocultable verdad; pero lo harán también por su honestidad y por la elevada escala de valores que lo caracterizan.

Existen muchos escultores y otros tantos escritores, pero son escasos los que forjan con inmanencia su propia personalidad, los que dan a su vida la armoniosa e inmaculada tesura de un poema. Este es el caso del maestro Távara Córdova.

Se han verificado cumplidamente estos matices en la personalidad del Dr. Távara Córdova y por ello nos hemos permitido invitarlo para que se integre a nuestra familia de la Universidad Alas Peruanas, para que sea ejemplo de nuestras generaciones e incentivo para la praxis universitaria, sobre todo en la Facultad de Derecho y Ciencias Políticas. Su vocación de maestro universitario lo certifica, más aún, para justificar nuestro anhelo.

La Universidad Alas Peruanas ha cumplido doce años de vida institucional, y en ese lapso hemos creado filiales y sedes descentralizadas que cubren todo el país. 
Los más de 50 mil estudiantes, 19 filiales, 6 unidades académicas descentralizadas, más de 3000 profesores, 700 trabajadores administrativos y personal de servicio, son testigos fehacientes y protagonistas de esta realidad en nuestra casa de estudios.

\section{Doctor Francisco Artemio Távara Córdova:}

En nombre del Directorio, del Rectorado, Decanos, Directores, Docentes, Funcionarios y Estudiantes, le impongo la Medalla de la Universidad Alas Peruanas que simboliza el espíritu de nuestro claustro; le entrego la Resolución que lo acredita como DOctor HonORIS CaUsa y el diploma correspondiente que certifica nuestro vínculo académico.

Le agradezco su aceptación, y asimismo extiendo mi gratitud a todos los que han tenido la gentileza de asistir a este acto inolvidable.

Trujillo, agosto de 2008 . 


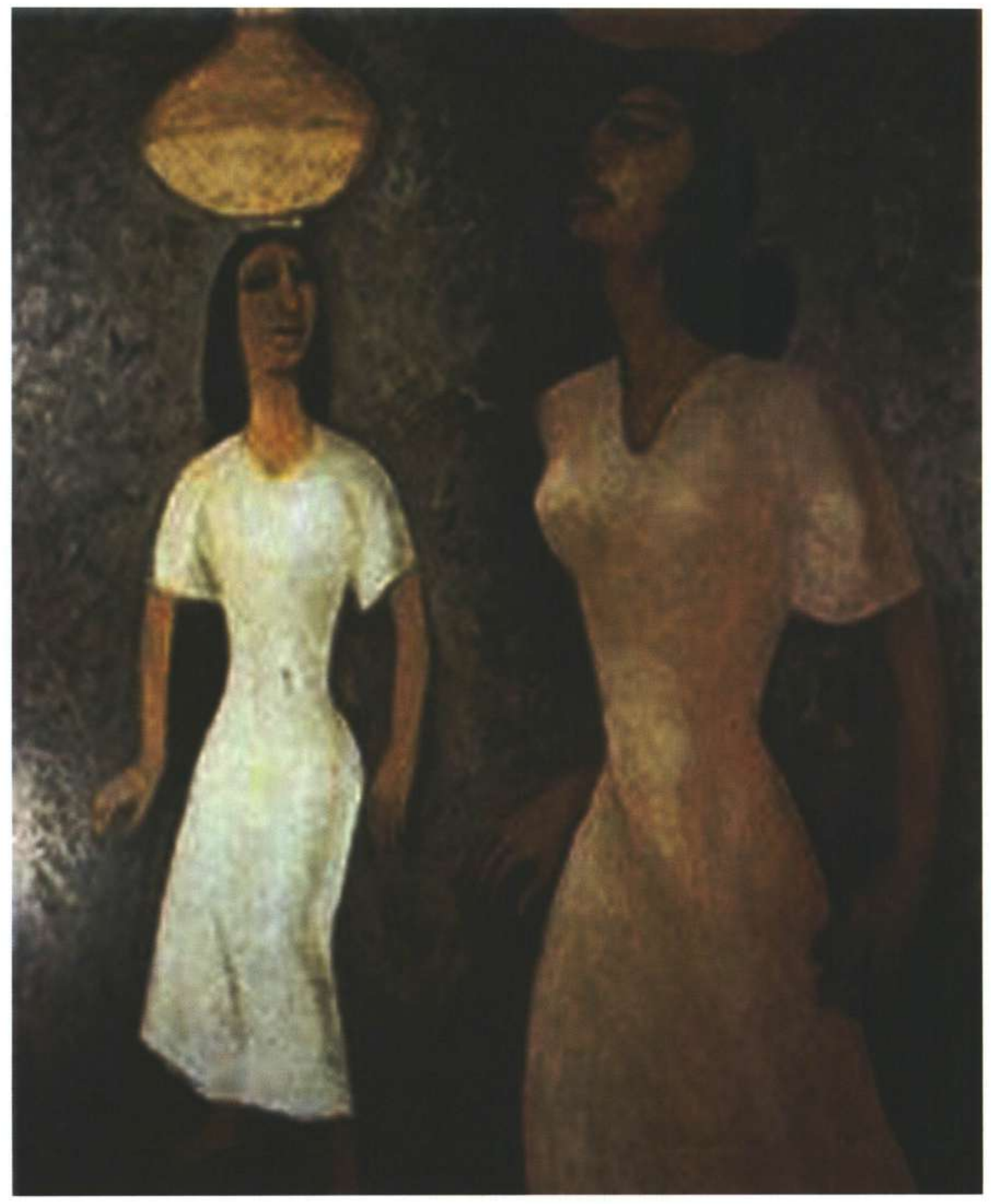

Mujeres de Ucayali 